voice about workplace matters and have gained a foothold in the corporate world as a consequence.

columns of working age (18-65 years) with mental health problems, and replaces Council Report CR86. It is produced at a time of unprecedented change, as the 'modernisation' teams prescribed in the National Health Service Plan are being introduced. 'Community care' still seems a meaningful concept in psychiatry, and has been retained. The document emphasises the range of partnerships that define modern community mental health practice.

Despite this, the role of the psychiatrist is proposed as prominent and crucial for the development and delivery of high-quality, humane services.

The document is clinically led and aimed at practitioners, local service planners and managers. Concrete figures have been quoted where there is adequate consensus. These figures are guides, not prescriptions, and aim to promote constructive dialogue, not replace it. The report was written by a group that included non-psychiatrists. The psychiatric members were drawn from within the College for their known expertise (rather than as representatives of faculties, which is the usual case). Consultations took place with all faculties and with a range of external stakeholders.

Chapter 1 outlines the vital partnerships, in particular those beyond the multidisciplinary team. These crucially involve partnerships with patients and their carers, but also voluntary and other nonhealthcare statutory services. Partnership is as much a state of mind as a series of managerial structures.

Chapter 2 outlines the functioning of

\section{Community Mental Health Care}

Council Report CR124, September 2004 Royal College of Psychiatrists, £7.50, 56 pp.

This is the third edition of the College's policy on community care for individuals have increasingly defined functions and procedures.

Chapter 3 deals with the modernisation teams (assertive outreach, crisis resolution/ home treatment and early intervention services for psychosis). It acknowledges the variation in their development nationally, and also the deviations from the prescribed models that have been developed within the very real staffing constraints under which they have been introduced.

Chapter 4 discusses the crucial issue of social care, both the role of the social worker within community mental health teams and the wider aspects of social care - accommodation, occupation and childcare. The rapidly rising significance of social inclusion and the move to combined health and social care trusts has sharpened the focus on this area, while reducing certainties.

Chapter 5 deals with the 'essential clinical partners' in community care primary care, substance misuse services, rehabilitation and forensic services. There is far greater variation in the forms of service provision within these specialties than in general adult community mental health teams. General principles of collaboration and common configurations are addressed, rather than detailed prescriptions.

Chapter 6 focuses on the issues of local variation and diversity. Hardly any locality in the UK now is 'typical'. Ethnic diversity challenges almost all urban services to ensure cultural sensitivity and, in some settings, highly specific configurations. Diversity includes the consistent differences found in all localities (e.g. gender, specific diagnostic groups which may demand different approaches such as acquired brain injury and personality disorder), as well as local high concentrations of specific groups (e.g. the homeless, refugees). 